\title{
POPULATION MOBILITY IN BAVARIA: SPATIO-TEMPORAL FEATURES AND MIGRATION FLOWS IN THE EARLY 21ST CENTURY
}

\author{
Alexandra Starikova \\ Department of Social and Economic Geography \\ Institute of Geography, Russian Academy of Sciences \\ 119017, Staromonetniy pereulok 29, Moscow: Russia \\ a.v.starikova@igras.ru
}

\begin{abstract}
The article presents the results of population mobility research at the territory of Bavaria. Different types of migration flows (resettlements, commuting, educational migration, etc.) within municipalities and through their borders, as well as between Bavaria and other parts of the country are analyzed. Spacetime features of population mobility are revealed. Main methods of analysis include delimitation of migration systems and calculation of human activity density. The study found that scale of population mobility within Bavaria is larger than migratory exchange with other parts of Germany. Commuting and other types of return population mobility take more important positions in the regional migration process.
\end{abstract}

Key words: population mobility, non-return migration, commuting, educational migration, Bavaria.

\section{Introduction}

Attention to international migration flows should not obscure the interest in research within countries. In the early 21st century spatial mobility of population at regional level grows, affecting many areas of human life no less than external migration. The picture of spatial mobility at the territory is created by different population movements including non-return migration (with change of place of residence), commuting, educational migration (movements of pupils and different types of students), tourist flows, etc. In the scientific literature studies comparing different types of spatial mobility are not rare (among others Kalter 1994; Abraham \& Schönholzer 2009; Pfaff 2009) but the main emphasis in them is placed on comparing resettlements with commuting. In this article different movements of people are examined together and an attempt to create complex picture of population mobility in Bavaria is undertaken. Special attention is focused on return mobility (commuting and educational migration), which according to W. Zelinsky's model of migration transition (Zelinsky 1971), becomes more intense at the stage of the postindustrial society, and migrants' behavior is increasingly based on motivations stimulating return movements.

External migration as well as high level of spatial mobility of population within borders of Bavaria are considered as one of the reasons for successful development and a pledge of further prosperity of the federal state (Popp 2006). High population mobility makes it possible to fill 
up gaps in labor force at local markets (by mobilizing internal human resources and increasing Bavarians readiness to participate in migration). This federal state of Germany has a virtually unbroken historical tradition and it is distinguished by the stability of borders and centers (settlements) that contributes to the stability of migration bonds. German scientists had conducting integrated studies of migration in Bavaria in the 1970s and 1980s, but later researches focused on narrower topics (adaptation of immigrants, issues of labor migration, etc.) (e.g., Roncandor 2004; Acker 2011; Ficklscherer 2011).

The purpose of this article is to reveal space-time features of population mobility in Bavaria both within its borders and compared to other federal states of the country. Movements of Bavarians and Bavarian visitors are considered from a geographical perspective: among other things it requires the analysis of migration flows directions as spatial expression of socioeconomic bonds between areas, delimitation of migration systems and their centers as well as calculation of human activity density (as an indicator of level of population mobility). In the research the following main tasks are solved:

- identification of trends and features of population mobility in Bavaria in different geographical scales (include both types of population: permanent and temporarily present on the territory);

- delimitation of migration systems for internal migration and commuting (these systems unite regions of emigration and immigration);

- development of the algorithm for calculating index of "summarized human activity" and its density for analyzing of population mobility.

\section{Description of the methods and information base of research}

In the study the primary sources of information about population mobility were publicly available statistical publications of Federal Statistical Office of Germany (Statistisches Bundesamt), Federal Employment Agency of Germany (Bundesagentur für Arbeit) and Bavarian state office for statistics (Bayerisches Landesamt für Statistik). In addition, the information collected during short-term field researches (carried out in 2010 and 2011) and database independently created by the author (consisting of different types of migration indices for year period from 2000 to 2014) were used. The study of migration processes in Bavaria was carried out within the framework of the migration systems theory and of the spatio-temporal approach in geography (time geography).

The theory of migration systems as pioneered by the Nigerian geographer A. L. Mabogunje in the 1970s (Mabogunje 1970) was developing by such researchers as J. T. Fawcett (Fawcett 1989), M. M. Kritz, L. L. Lim and H. Zlotnik (Kritz et al. 1992), etc. Definitions of migration systems are different. For example, Russian researcher I. V. Ivakhnyuk (2007) defines a migration system as a group of countries linked by relatively large and stable migration links. In this article migration systems unite regions of emigration and immigration and represent primary areas of migrants' attraction to cities (as centers of the systems). Relations between regions and cities are determined by migration flows. To the delimitation of migration systems by the data about size of these flows coefficients of migration attraction are calculated. Migration systems serve as a reflection of labor, economic, social and other ties.

Coefficient of migration attraction is based on the coefficient of connection used in the works of German researchers (Anbindungskoeffizient) for the determination of local labor markets boundaries and calculated as a proportion of the total number of employees living in region $i$ and number of commuters from them to region $j$ (Eckey et al. 2006; Kropp \& Schwengler 2008). 
In the study the coefficient of migration attraction $A_{i j}$ is an indicator of the importance of a district or a city as a goal of migration for residents of other areas, regardless of the size of the incoming migration flow. It is calculated for two types of flows - non-return migration and commuting within Bavarian borders:

$$
A_{i j}=\frac{M_{i j}}{\sum_{j=1}^{m} M_{i j}}
$$

where, $M_{i j}$ - the number of migrants from region $i$ to region $j ; \sum_{j=1}^{m} M_{i j}$ - the total number of mi-

grants from region $i ; m$ - number of Bavarian administrative divisions (districts and independent cities).

As a result, maps of migration systems were constructed (see Fig. 6 and Fig. 7). On maps the values of the migration attraction coefficient and directions of migration flows are indicated by arrows (only for flows with coefficient $A_{i j} \geq 0.10$ ). Within the study framework level of the migration attraction is estimated as weak (at the values of the coefficient from 0.10 to 0.25 ), middle (from 0.25 to 0.40 ), strong (from 0.40 to 0.55 ) or very strong (>0.55).

Population mobility analyzes based also on time-geographical approach which formation began in the 1960s due to scientific activity of famous Swedish geographer T. Hägerstrand (1970, 1985). Time and space in terms of time geography are resources directly involved in the structure of human life, representation of phenomena occurs in time-space (Lenntorp 2003). Accurate measurement of time is of great importance in the study of everyday life and people's activity (including an analysis of spatial mobility) due to one of the basic theses of time geography: all individual's actions need time to fulfill them (Ellegård 1999).

Ideas and methods of time geography is especially useful for the studying of return population mobility (its various types play a major role in the formation of a general migration picture in modern society) because in time geography the central is the principle of return which asserts that an individual carrying out activities outside his home during the day usually come back at night for sleep, eating, resting and getting a sense of peace (Lenntorp 1976). Within the framework of time geography, it is possible to describe and analyze the relationship between activities, location and movements of individuals (Lenntorp 1976) that is especially important because of progressive territorial separation between places of residence, work, study and rest (associated with the complication of the spatial organization of people's activities) and increases the relevance of modern researches within the time-geographical approach. Accounting of time factor in migration studies is mostly done by analyzing of continuous trajectories (space-time paths) of individuals (Lenntorp 1976), that is not suitable for the purposes of this study. Therefore, the author offers his own method of time accounting by calculation of 'summarized human activity' and 'human activity density'. Furthermore, such indices also were applied as they allowed to move away from the study of places of permanent residence (that today in a certain sense is fictitious) to places of actual human activity (in other words, transition from analysis of population distribution to spatial and temporal localization of its activity).

The methodological procedure proposed by the author is a possible method of analysis within the framework of the time-geographical approach. In the analysis of population mobility from the standpoint of such approach time spent by individuals (students participating in the educational migration, commuters, tourists) in each place and spent on movement by one or other 
means of transportation is considered. This allowed us to assess the contribution of different migration types to the general migration picture and to develop a complex view of migration processes at the researching territory, which will help in solving problems of traffic, housing or trade more effectively. Also, unlike the mass and density of the permanent population, which fixed by statistics as a rule at the end of a calendar year, indicators of human activity are calculated based on data on time, spending by individuals in a given place during the whole year.

The index of 'summarized human activity' is the actual number of man-hours per year lived by permanent population and by population temporarily present on the territory (like tourists and commuters). The index of 'human activity density' $\mathrm{T}$ is the ratio of 'summarized human activity' to the total area of the territory:

$$
T=\frac{T_{i}+M_{1}+D-M_{2}-O \pm t}{S} .
$$

In the formula $T_{i}$ is the number of man-hours lived by permanent population of an administrative division (district or independent city) on its territory during a year. Permanent population include residents who have lived in the administrative division a calendar year, who were born or died here during this year, resettlers and immigrants. Resettlers and immigrants lived here less than a calendar year, but the statistical data does not allow to know how long, so the time of living for calculating 'human activity density' for resettlers and immigrants is equal to half a year. Thus, the number of man-hours $T_{i}$ consists of two parts: $T_{i 1}$ and $T_{i 2}$, where $T_{i 1}$ is the number of man-hours for residents had lived here a whole year, $T_{i 2}$ is the number of man-hours for people had lived on the territory about six months. $T_{i 1}$ is equal to the population as indicated in the statistics on December 31, minus value of births and resettlers (departures to other administrative divisions), multiplied by 8760 hours ( 365 days with 24 hours each). $T_{i 2}$ is the amount of births, deaths, arrivals and departures of resettlers, multiplied by 4380 hours (182.5 days with 24 hours each).

Component $M_{1}$ reflects time spent here by commuters. The ways of calculating depend on the available information. It is possible to calculate $M_{1}$ value, if the total number of hours for a year worked by people at the territory of administrative division and proportion of commuters among workers are known. If such data are not available, the calculation can be made more roughly (considering the average number of working days in Bavaria is 220 per year, and the standard working day lasts 8 hours). It can be assumed that each commuter spent an additional 2 hours in the district where his workplace is located: 45 minutes for lunch and 75 minutes for various purposes (it is shopping, entertainment, informal meetings, courses for additional education, sports, etc.). In the article $M_{1}$ value was obtained as number of man-hours multiplied by share of commuters among all workers (plus additional time in the district or city where commuters work).

Component $D$ is the number of man-hours spent by tourists in administrative division. $D$ value is equal to the number of tourist arrivals per year multiplied by average length of stay (in days) and by 24 hours.

Component $\mathrm{M}_{2}$ is subtracted from the sum of the previous components in the calculation formula. $M_{2}$ value is the number of man-hours spent by administrative division residents participating in commuting process and working outside the territory of the division. It is taken into account that a part of commuters refers to full-time employees (the number of man-hours for one employed is 1760 for 220 working days), other are part-time workers (they work out an average of 792 hours per year). In 2013 the share of full-time workers in Bavaria was 75\%, while 25\% fell on some form of part-time employment. In addition, time for the journey to and from work place 
is considered, based on the average travel time in Bavaria and the proportion of migrants forced to spend such time. Thus, $M_{2}$ is the sum of man-hours worked by commuters, spent on the journey and conducted additionally at the place of work (additional time is calculated in the same way as for the $M_{1}$ value).

Another formula component subtracted from the sum is $\mathrm{O}$ value. It is the number of man-hours spent by residents of administrative division on vacation or on business trips outside the place of residence. There is no comprehensive statistics on this topic. There are certainly Bavarians who, for one reason or another, spend the entire year within their place of residence but it is not reflected in statistical sources. Therefore, $O$ value is calculated conditionally: it is assumed that each resident spends 30 days outside the area of residence during the year. In other words, $O$ value is equal to the permanent population of a given administrative division, multiplied by 720 hours (30 days for 24 hours).

Component $t$ is the number of man-hours that residents spent in different places (educational migration trips, shopping, visiting of relatives, etc.) and does not apply to the cases mentioned above. In real-world conditions collection of such data is difficult, therefore, time spent on these trips is not included in the calculation of the index of human activity density.

\section{Main types of population mobility and their features}

At the beginning of the 21st century Bavaria took one of the key places in Germany in terms of spatial mobility of population. This federal state stands out in the country for many indices, it has stable migration population growth and positive migration balance with most of the federal states (excluding Hamburg, Berlin and Schleswig-Holstein). Powerful incoming flows alongside with aggregate of non-return migration indices make Bavaria one of the main regions focusing internal migration flows in Germany. Different categories of resettlers, especially highly qualified specialists, are attracted to Bavaria due to high level of its economic development.

In Bavaria the importance of return spatial mobility is also growing, especially commuting (include cross-border flows from neighboring countries). For the period from 2001 to 2013 the number of commuters working outside municipality of residence has increased by more than half a million people. Statistical information about other types of return mobility (educational migration, tourist flows, trips with cultural goals, etc.) is not sufficient for a broad review (especially not enough comparable data series for different administrative divisions' levels), although in Germany such migrations are widespread. For example, in 2011 every third resident in the country studied outside his municipality (Seibert 2013), so he was a participant of educational migration. Bavarian schoolchildren and students also have high spatial mobility: two-thirds of them regularly go to school or other educational institution in municipality different from place of residence. The spatial mobility of Germans also reveal itself in weekly, seasonal and other regular or episodic trips such as visiting medical facilities, big shopping centers located in places accessible for several settlements immediately, vacation and temporary residence in second homes.

Tourism is also an integral part of country's economy and plays an important role in the life of Germans. Germany is among the top ten countries in the world in terms of the foreign tourist number (31.5 million people in 2013) and is one of the most important destinations in Europe (48 million trips in 2013) along with Spain (51 million trips). Bavaria is the main tourist destination of all Germany: in the total number of arrivals and overnights its share is $20 \%$.

In the article three types of population mobility within borders of the federal state are analyzed: non-return migration (resettlements), commuting and educational migration. 


\section{Non-return migration}

Since the early 1940s immigration was an important factor of development in Bavaria significantly due to the immigration of elite (Kramer 2008). High level of economic development attracts into Bavaria migrants of different categories (firstly highly skilled workers required at high-tech industries). From 2000 to 2013 more than 1.8 million people moved to Bavaria as resettlers. Among other federal states Bavaria is also distinguished by non-return migration flows in its own territory. Resettlements within the borders of the federal state significantly exceeds the external migration turnover: for the period 2000-2013 the number of resettlements within Bavaria has grew (as a whole), fluctuated from year to year (the greatest value was 351.2 thousand people in 2013) and exceeded the number of cross border resettlements by $36 \%$ (more than 4.5 million people changed place of residence at Bavaria area). So, it reflects the leading role of internal migration in the migration process in Bavaria. Volumes, balance and dynamics of non-return migration by administrative regions (Bezirke), districts (Landkreise), independent cities (Kreisfreie Städte) and municipalities (Gemeinden) have pronounced differences.

The main zone with increased intensity of internal non-return migration (by migration turnover ratio) represent a strip extending from Nuremberg to Munich. It is "stem axis" passing through key economic and cultural centers of Bavaria and indicating the most successful and dynamic part of the federal state. Moving away from with axis, the intensity of migration is decreasing (Fig. 1).

Population growth due to resettlements was noted at the administrative regions level only in Upper Bavaria and Middle Franconia, at the next level in half of independent cities and some sided districts and already in $60 \%$ of the municipalities. Migration growth is naturally large in Munich

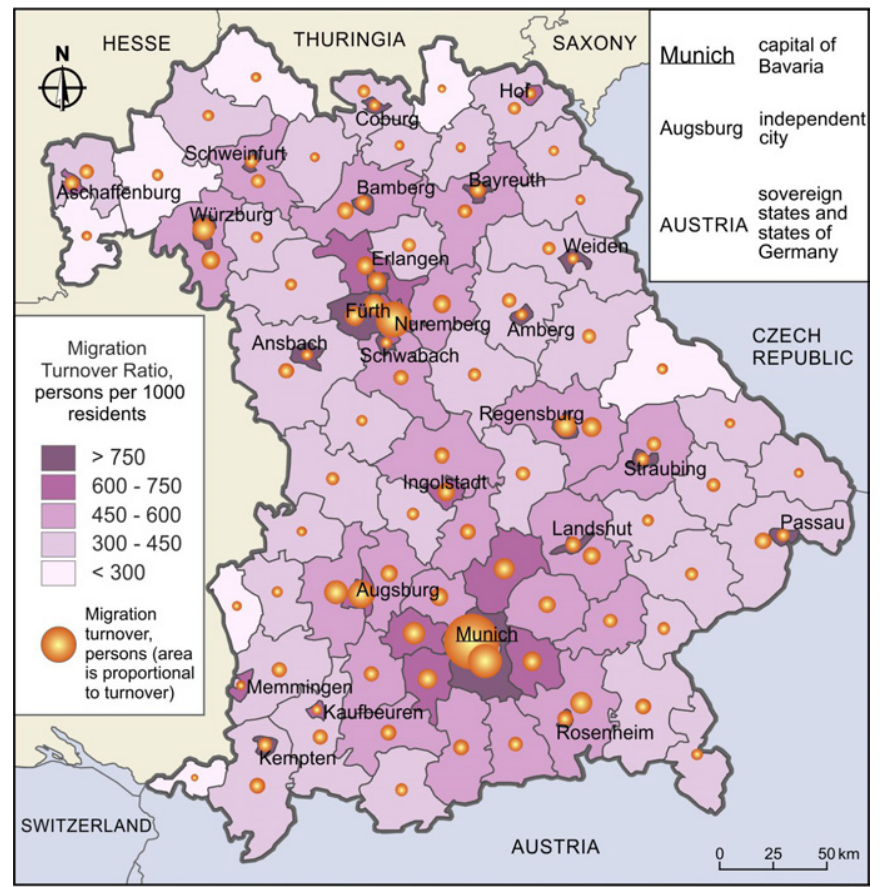

Figure 1. Migration turnover in districts and independent cities of Bavaria in 2004-2013 (calculated from data of Bavarian state office for statistics) Source: author's own elaboration 


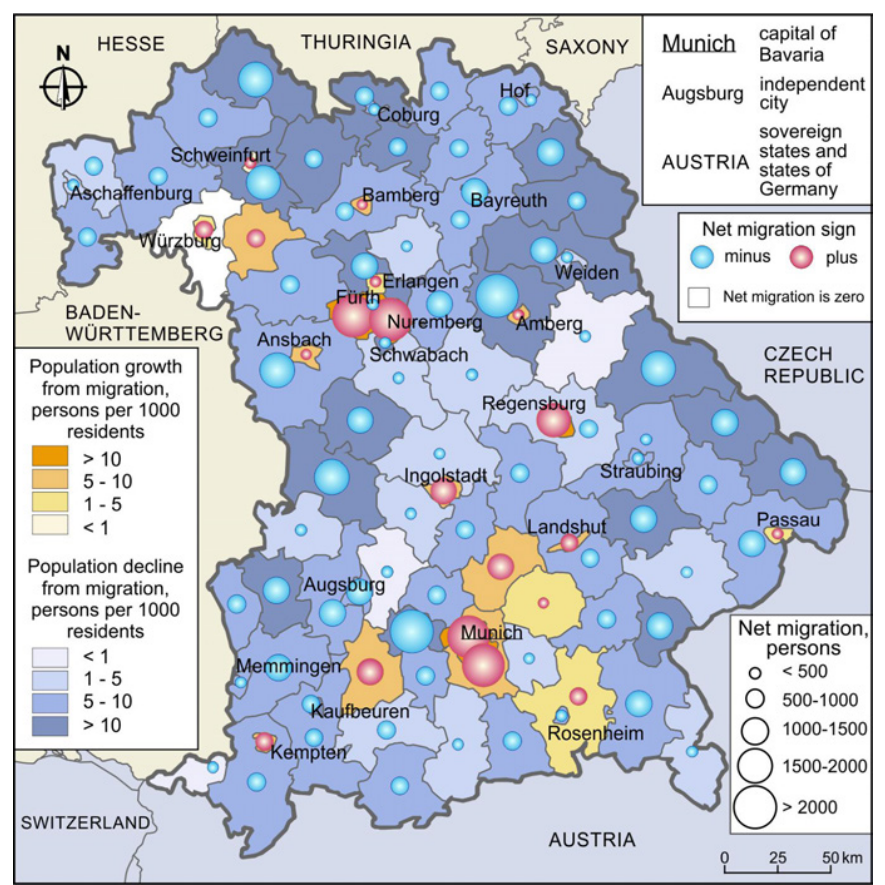

Figure 2. Net migration in districts and independent cities of Bavaria in 2004-2013 (calculated from data of Bavarian state office for statistics) Source: author's own elaboration

- main city of Bavaria, Nuremberg remaining behind it and within they agglomerations. About 78\% of cities and districts lose population because of negative migration processes, especially in the areas adjacent to the new federal states of Germany (Thuringia and Saxony) and the Czech Republic, sometimes near centers of migrants' attraction (Fig. 2).

The largest agglomerations of Bavaria (with centers in Munich, Nuremberg and Augsburg) as the main targets for immigrants are characterized by multidirectional migration dynamics. The sharp migration growth in the Munich metropolitan area in 2006 was connected both with the active creation of jobs in infrastructure projects (during preparation for the World Cup) and with the successful development of suburbs that combine the potential of proximity to the Munich and their own attractors. The Nuremberg agglomeration was characterized by stable migration growth, while in Augsburg agglomeration there was an outflow of residents, despite a stable growth in the agglomeration core. In Augsburg agglomeration flows of two directions are important: the steady influx of young people into numerous universities and research centers (students living in the city during the education period) and the departure of young specialists beyond the borders of the agglomeration at the end of their studies.

Five groups of districts and independent cities are identified based on the dynamics of non-return migration flows within Bavaria (from 2004 to 2013) (Fig. 3):

-The first group of districts has positive migration balance. These are areas with an advantageous position between important economic centers, attracting big business into innovative economic sectors. 


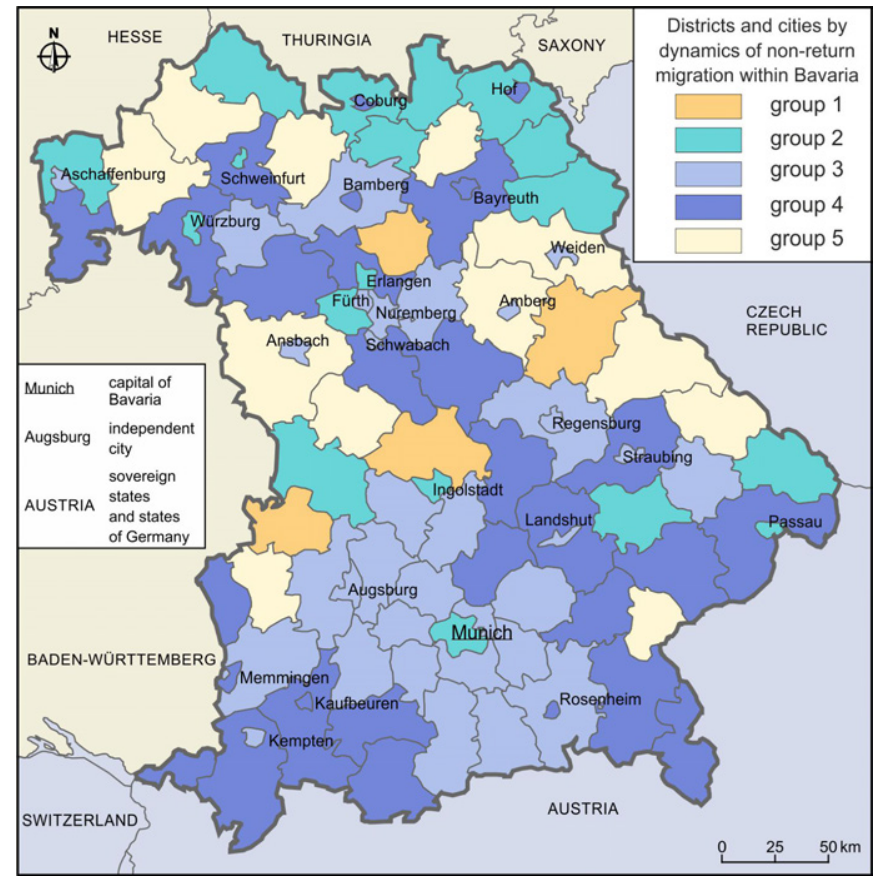

Figure 3. Groups of districts and independent cities of Bavaria by dynamics of non-return migration in 2004-2013

Source: author's own elaboration

- The second group includes "winning" districts. This is city of Munich and the northern internal borderland. Here in the period after the Great Recession 2008-2009 many people found new places for living and working, as the authorities and employers offered them a favorable economic environment through the creation of new enterprises and the development of tourism sector.

- The third group are "lost" districts. They suffered under the impact of the Great Recession (elevation of migrants' inflow above the outflow ended with the beginning of the crisis).

- The fourth group has stable negative migration balance and includes places near big cities as well areas where development impulses lie beyond borders of Bavaria (like town of Neu-Ulm on the right-bank of the Danube on the border with Baden-Württemberg federal state).

- The fifth group are the outlying districts with an outflow of residents, but the numbers of arrivals and departures are getting closer to each other (among them the area near Czech Republic, the least developed in the whole Germany).

Typology of 2056 Bavarian municipalities by the features of non-return migration (Fig. 4) was based on algorithms for automatic cluster analysis and data for the period from 2009 to 2013: net migration, migration turnover, population growth or decline from migration (persons per 1000 residents), migration turnover ratio (persons per 1000 residents), migration effectiveness (number of outflow persons per 100 inflow persons). Typology using was discover: 1) the main centers of migrant's attraction (9 independent cities, where the effectiveness of migration is high); 2 ) secondary centers of migrant's attraction (medium-sized and small cities, some rural municipalities leading in terms of intensity and effectiveness of migration exchange, but not to its scale); 3) peripheral centers of migrant's attraction (numerous and diverse municipalities united by very strong 


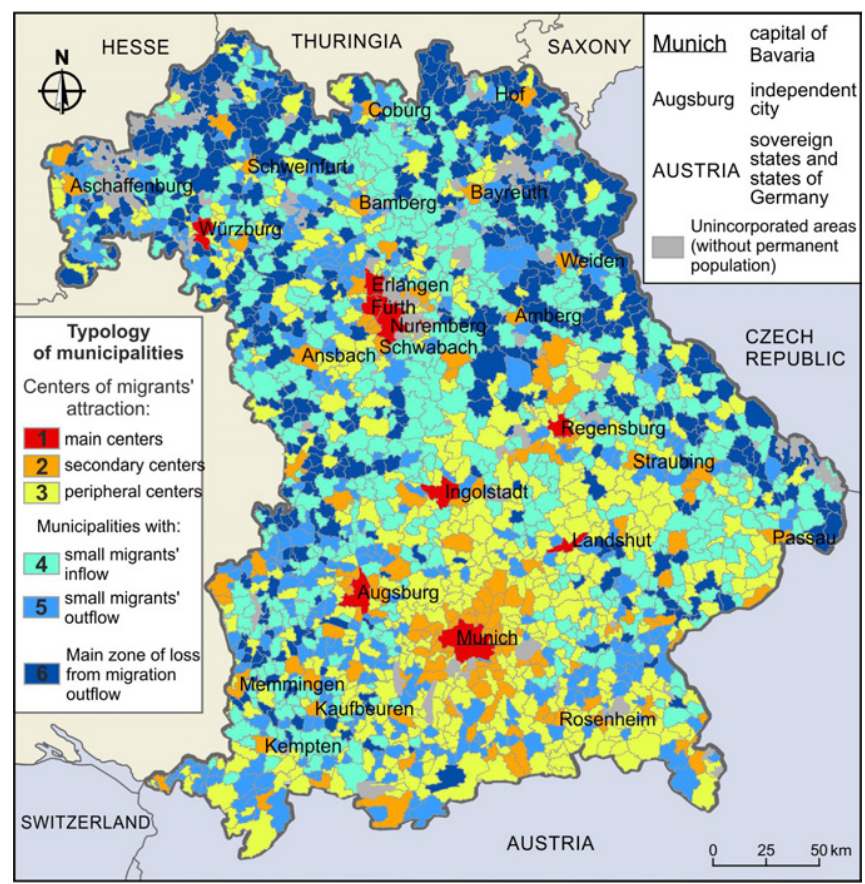

Figure 4. Typology of Bavarian municipalities by the features of non-return migration in 2009-2013 (calculated from data of Bavarian state office for statistics)

Source: author's own elaboration

effectiveness of migration turnover); 4) municipalities with a small migrants' inflow (most often located in the central part of Bavaria from the northern border to Ingolstadt); 5) municipalities with a small migrants' outflow (dispersed and not retaining most of resettlers); 6 ) the main zone of loss from migration outflow ( $24 \%$ of total municipalities number, which have the worst migration indicators).

In general, territorial structure of non-return migration identified by the typology of the Bavarian municipalities (as well as by separate migration indices) may be summarized as follows: everything is subordinated to the division along the "center-periphery" line. There are: a multiscale "center" (it forms a mega-core in the central-southern part of Bavaria together with separate smaller cores), semi-periphery (municipalities of the 4th and 5th types) and the periphery (it is asymmetric in the north-south direction and consists of municipalities of the 6th type).

Potential effects (economic, social, etc.) of migration processes and their changes are easily traced in the peripheral territories noted above. For example, regions along the border with the Czech Republic need to reduce the migration outflow (and, in the future, change the direction of migration flows), that can improve the economic situation. Today these areas suffer from relative isolation and weakness of transport infrastructure, and some of their residents choose moving to a new place of residence (primarily in the city of Regensburg and its suburbs) in order to make better living conditions. For the influx of migrants to the border areas in turn it is necessary to stimulate industrial growth and reduce unemployment: these measures will keep potential labor force from resettlement (as is already observed in the district of Schwandorf with expansion of the Wackersdorf Innovation Park). 


\section{Commuting}

In the early 21st century commuting is gaining increasing importance in the processes of spatial mobility of the population in Germany. According to commuting dynamics, Bavaria stands out among all German federal states (as too for non-return migration). In Bavaria the largest increase in the number of commuters among German states was recorded; from 2004 to 2014 such number grew by more than a quarter, exceeding 2.2 million people for inter-district migration and 3.1 million people for inter-municipality migration. The main contribution to the number of commuters is made by migrants within borders of Bavaria. Along with the total number of commuters in Bavaria a gradual increase in their share among the employed takes place $(41.7 \%$ in $2004,44.3 \%$ in 2014). This trend typical for the whole country evince here even more (in Germany the share is about 33.0\%). Against the backdrop of multi-directional factors (including such strong ones as the Great Recession 2008-2009), the geography of commuting was expanded, and the commuter ranks were actively filled up. In 2013, their number was almost 5.5 times higher than the number of resettlers. The indicators of commuting were influenced by both general processes and local labor market and employment features. The rise in the total number of jobs and in the share of part-time jobs have led to growth of commuter number. Spread of so-called marginal employment (short-term, one-time, often low-paid jobs, which becomes a solution for those who lost permanent work) caused a reduction in the number of commuters in individual years. In 2003-2014 years commuting in Bavaria had features discussed below.

In comparison with non-return migration commuting gives participants several advantages. It allows people to find the best work place and avoid material and other costs arising during the resettlement to a new place of residence, at the same time workers can be kept from resettlement by different reasons, for example, due to composition of the family or desire to preserve social contacts (Abraham \& Schçnholzer 2009). Authorities of Bavaria and private companies often create jobs especially attractive for commuters. This policy called "professional mobility management" is aimed to increasing availability of enterprises for commuters, reducing the stress level of workers from regular long trips to work, etc. Residents are offered financial support (special fares for public transport and tax deductions). Intercept parking lots and other transport infrastructure for commuters are created. In addition, "professional mobility management" makes it possible to use potential effects of changing of commuting flows directions, that is especially important in times of economic crises. For example, in 2009 administration of the Audi plant in Ingolstadt attracted to work the dismissed employees of Schaeffler company, whose plant is located near Nuremberg (almost $100 \mathrm{~km}$ north of Ingolstadt). Not only migrants and territories receiving them benefit from commuting (obtaining workforce and customers of services sectors), but also migrant-supplying regions (thanks to commuters' tax deductions, besides these people can still be attributed to potential local workforce if demand for their labor will increase).

At the level of administrative regions, Upper Bavaria and Middle Franconia were the "employers" attracted commuter flows. At lower administrative levels, positive net labor migration was revealed at the largest urban centers, as well as some urban and rural municipalities dispersed throughout the state. Remaining areas (especially adjacent to the foci of commuting) was served as "bedroom communities" and suppliers of labor force. In the research five types of municipalities with different needs for commuters were identified (based on calculating the ratio of the total number of jobs to the number of all working residents): 1) "bedroom communities" with a shortage of jobs (often rural municipalities with a small population and capacity of the labor market); 2) communities with a modest job deficit (rural municipalities, as well as small and medium-sized cities); 3) communities in which most of their own workforce is employed (small, medium and some 
large cities, including Munich and Nuremberg); 4) communities with a surplus of workplaces (mainly large cities needing of an inflow of commuters); 5) communities-employers. Last one represents employment centers (rural and small urban municipalities, especially in the Munich economic zone), where migrants are the main labor force. Here large firms have created so many jobs that their number is close to the number of residents or even surpassed it. One of the outstanding examples is the city of Dingolfing in the east of Bavaria; here for more than 27 thousand jobs, 23 thousand applies to commuters. At the same time population of Dingolfing is 19 thousand and the main employer is BMW automobile plant with 18 thousand jobs.

In Bavaria, the individual radii of commuting and travel time spend by migrants for trip to work place are increasing. In 2013 the average trip distance (in one direction) was 16.9 km for inter-municipality and $26.5 \mathrm{~km}$ for inter-district migration. The rise in the radii of commuting is indicated by increase in the proportion of workers moving daily from home to work distances greater than 25 $\mathrm{km}$ from $17.6 \%$ in 2004 to $18.4 \%$ in 2012. Part-time workers and employees with low educational levels (among them the share of commuters which doesn't move farther than for $10 \mathrm{~km}$ from place of residence is the highest) prefer short trips. Highly qualified specialists often choose long distances (the reasons include territorial differences in pay level, prospect of career growth, etc.). Travel time of commuters enlarges together with the distances growth. From 2008 to 2012 the number of Bavarians which spent daily for their trip more than 10 minutes has increased noticeably. The share of migrants that traveled to work from 30 minutes to an hour has rose the most significantly (from $16 \%$ to $22 \%$, most of them live on the periphery of major Bavarian cities and agglomerations). For trips to work Bavarians actively use motor vehicles (in 2012 they were chosen by three of the four commuters, especially residents of small towns and municipalities). The number and share of migrants choosing intercity high-speed trains is increasing, which can be associated with a tendency to enlarging of trips distances.

Return population mobility has very mosaic spatial structure as compared with non-return migration mostly due to the fact that: 1 ) distances of commuting are shorter (for inter-district migration 3 times, for inter-municipality migration almost 6 times); 2) average number of trips many times exceed the same indices for resettlements.

\section{Educational migration}

This type of spatial mobility includes daily or long-term trips from home to places of study and back (within municipalities of Bavaria and across their borders). Educational migration is an important part of regional migration patterns and is characterized by its own territorial structure. Wide choice of educational institutions, developed transport infrastructure, tax benefits and state support to students in Bavaria is a good basis for such migration. Bavaria in Germany is noted for low cross-border mobility of students and at the same time very high mobility in the territory of its "own" federal state. Number of educational migrants in Bavaria, their traveled distances and time costs are growing every year.

There are pronounced differences in average radiuses of trips, time costs and preferences of used transport among students and schoolchildren. The proportion of commuters among students in Bavaria is higher than among workers (66.5\% and $62.6 \%$ in 2005 , respectively), the average distance of study trip approximate to the distance of commuting across municipality borders (14.6 km and $16.9 \mathrm{~km}$ in 2012, respectively). The longest trips in Bavaria are made by students of vocational schools ( $26.2 \mathrm{~km}$; such figure for schoolchildren is $7.7 \mathrm{~km}$, for students is $23 \mathrm{~km}$ ). Time costs depend on the category of students, their place of residence and distribution of educational institutions in the territory. Only for five years from 2008 to 2012 the proportion of students 
who spent less than 10 minutes on study trip decreased from $30 \%$ to $25 \%$, while for all others the time costs are increased. For study trips Bavarians use public transport first of all. Over a third of pupils (primarily schoolchildren) choose buses as the main means of transportation between house and school. Personal motor transport is preferred by pupils of vocational schools, there are no obvious priorities for university students.

The general background of migration process is formed by a relatively uniform network of schools, regularity of schoolchildren trips and small distances limited by the level of one or a few adjacent municipalities. A pronounced "relief" against this background is created by trips of higher educational institutions students and pupils of vocational schools. The main centers of educational migration (in terms of study places number and share of migrants among students) are the largest Bavarian agglomerations and cities (primarily Munich and Nuremberg) with surrounding areas, as well as separate areas with training centers of large companies (for example, the Center for Professional Training of "Wacker Chemie" in Burghausen).

Students make a huge contribution to spatial mobility, and higher education institutions in the largest Bavarian cities serve as its focal points. Universities form their own zones of influence in the territory of the federal state (Fig. 5): these zones are the areas of residence of the probable participants of educational migration. The average distance of trips to universities $(45 \mathrm{~km})$ is almost twice as much the average distance for all higher education institutions. Rated radii of study trips are the broadest for students of the universities of Munich $(84 \mathrm{~km})$, Regensburg $(56 \mathrm{~km})$ and Augsburg $(54 \mathrm{~km})$. The main feature of educational migration bonds in Bavaria remains their

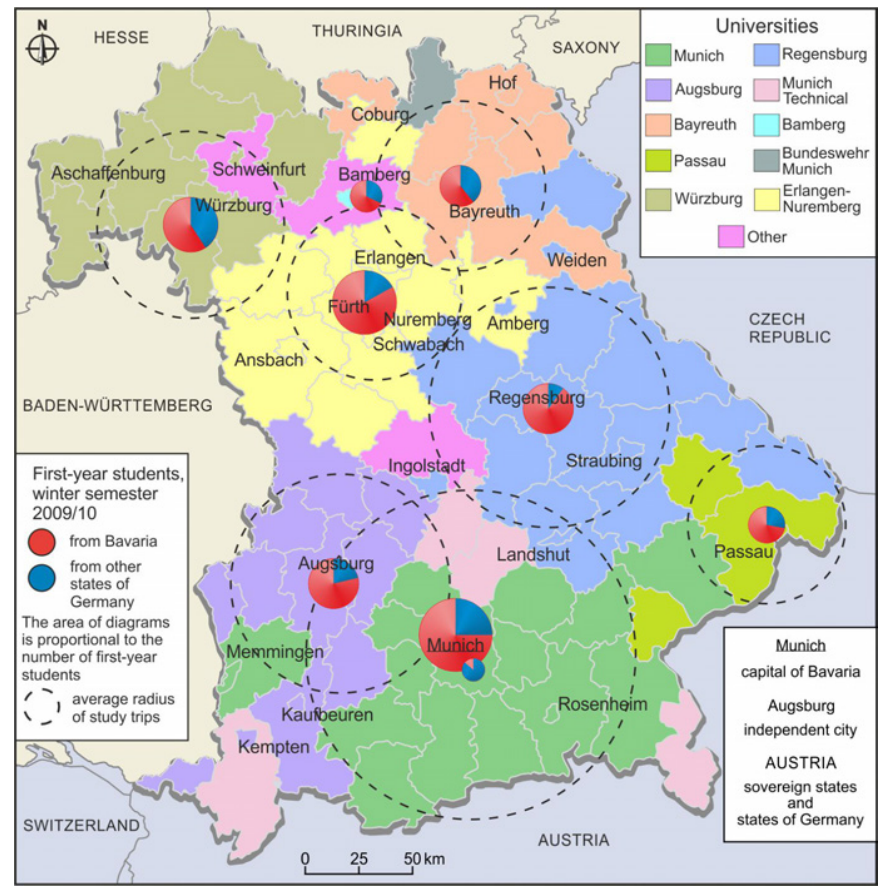

Figure 5. Educational migration centers and areas of residence for potential participants of migration to them in 2010 (according to data on first year students of leading universities from Bavarian state office for statistics) Source: author's own elaboration 
regionality. At the same time, university educational migration zones often correspond to Bavarian cultural and historical areas (for example, students from Upper Palatinate and Lower Bavaria come to Regensburg University).

It can be pointed that educational migration has an important socio-economic significance: it gives young people (who usually gravitate to change place of residence and to have new impressions) chances for moving up social and corporate ladder. The migratory outflow of young people changes population number and demographic structure in regions supplying and receiving migrants, affects labor markets. Thus, the development of an educational institutions network should consider potential directions of migration. For example, among young people in Bavaria are in demand vocational schools (at the beginning of 2010250 thousand people educated there, for comparison number of university students were more than 350 thousand), but they are placed non-uniformly on the territory causing (especially at the peripheral territories) to study away from home. However, some regions, even peripheral ones, thanks to large vocational schools (in districts Berchtesgadener Land or Garmisch-Partenkirchen), are aiming at meeting of local educational demand and keep potential migrants in the local labor market (districts defined above need workers for tourism industry, agriculture, forestry), reducing the negative effects of resettlements.

\section{Analysis of migration systems and human activity density}

The research of spatial mobility within the framework of migration systems theory and the spatio-temporal approach allows structuring two sides of the phenomenon - movement of people in space and its results.

\section{Migration systems delimitation}

In the research delimitation of migration systems formed in Bavaria in the process of non-return migration and commuting was carry out based on the migrants' flows data for 2004 (2003 for commuting), 2009 and 2013. All systems were divided into three types: main systems, their subsystems (if the size of migration flows to the system center does not allow them to be considered independent) and peripheral systems.

It was established that with time the boundaries between systems shift, systems change their type, but their centers tend to remain the same. Due to the stable existence of a larger subsystems number the territorial structure of commuting is more complex than territorial structure of the non-return migration. Analysis of migration systems has shown dominance of two centers of attraction for commuters and resettlers (Munich and Nuremberg), such result reflects the bipolarity of the Bavaria spatial structure.

To the biggest main systems belong those that have centers in Munich and Nuremberg. Munich systems identified according to data on non-return migration and on commuting are in the lead in terms of the number of flows form them and the number of migrants. Both systems include central part and subsystems (Fig. 6; Fig. 7) with the convergence of migration flows in cities: 1) for non-return migration system - Augsburg, Ingolstadt, Rosenheim, Passau; 2) for commuting system - Augsburg, Ingolstadt, Rosenheim, Landshut, Straubing. The Munich system of non-return migration (as well as its commuting system) is formed by the majority of districts and cities of south Bavaria, for which high mobility of the population is characteristic. An important difference between non-return migration systems and commuting systems is the presence of distant 


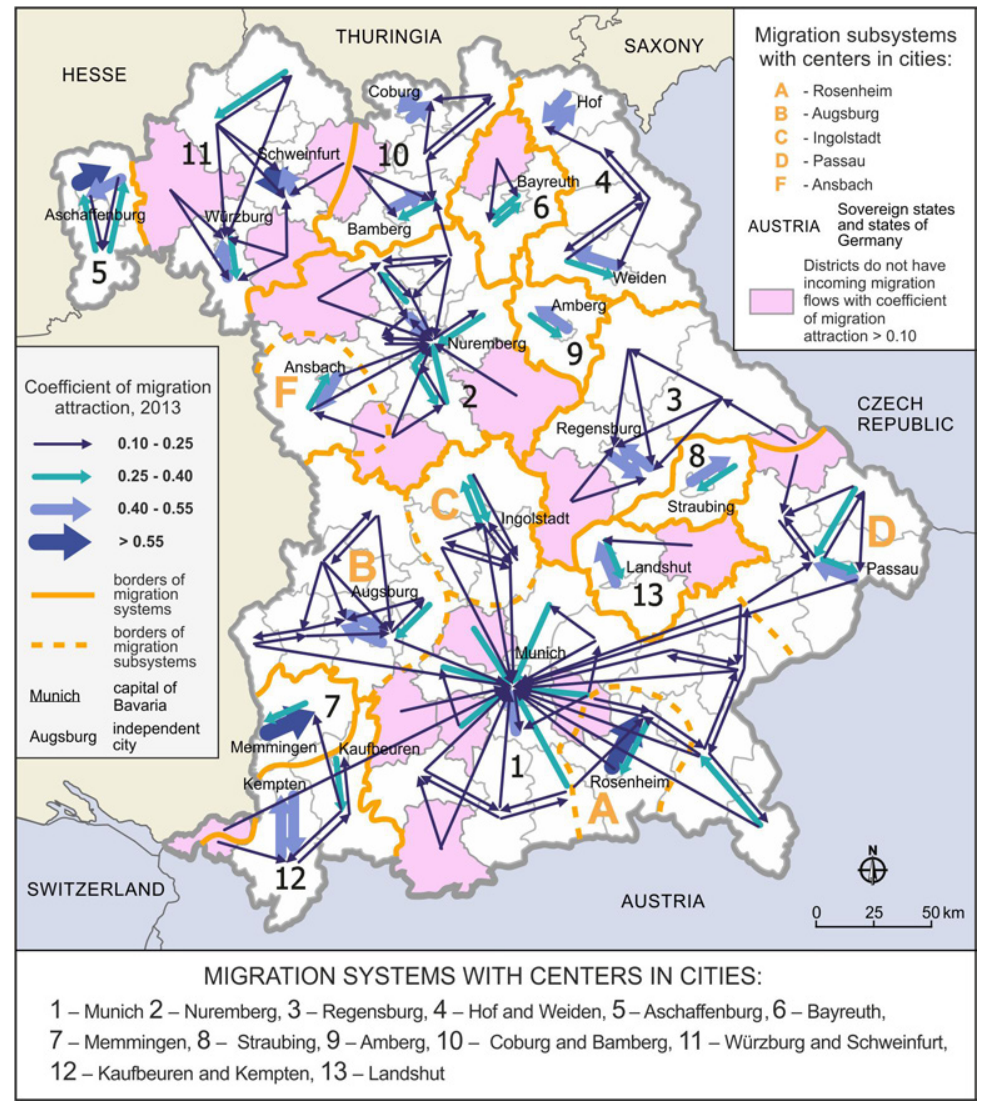

Figure 6. Migration systems, subsystems and their centers for non-return migration between districts and independent cities of Bavaria in 2013 Source: author's own elaboration

migration links (though weak) in the first system type. There are few of such links in the commuting systems, but according to the tendency to increase of the commuting distances, these links will arise, and the commuting system will expand. Both types of Nuremberg migration systems are formed by territories practically coincide with the Middle Franconia region. The borders accuracy and the system compact size explained by the Nuremberg role as cultural and economic capital of the Franconia historical region. Unlike Munich systems, the Nuremberg commuting system has only one subsystem (center in Ansbach), in its non-return system subsystems have not formed.

Regensburg forms the third significant area of migrants' attraction. Both its systems are smaller in area than Munich and Nuremberg systems, but coefficients of migration attraction are strong. Non-return system of Regensburg builds up new ties from the beginning of the 21st century, attracting resettlers from the low developed eastern borderland. In the commuting system there is a tendency to narrow of primary attraction area of the central city.

Numerous small peripheral systems have heterogeneous internal structure and are divided into two groups: 1) systems consisting of a core city and surrounding area; 2 ) systems with several centers with a general migration zone. 


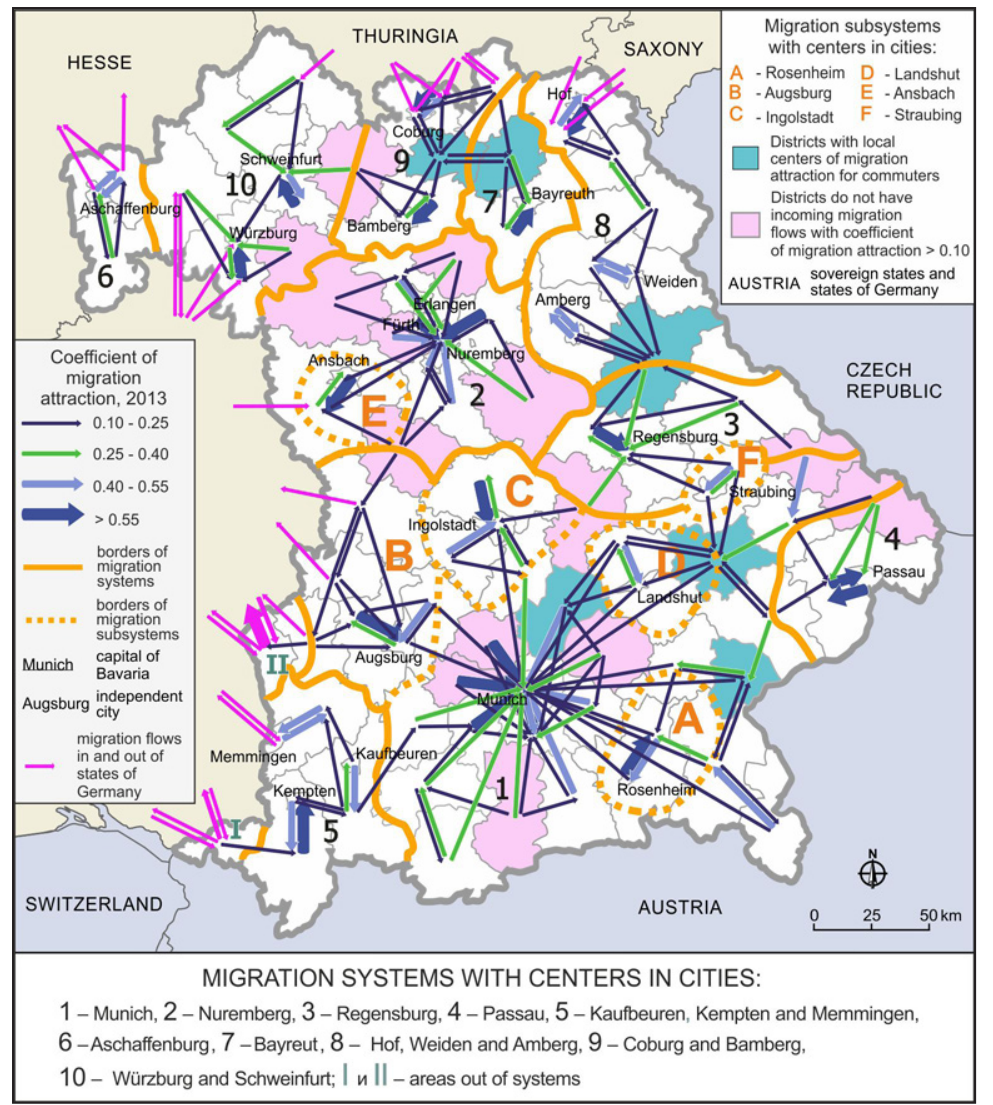

Figure 7. Migration systems, subsystems and their centers for commuting between districts and independent cities of Bavaria in 2013 Source: author's own elaboration

Presence of districts with local centers of migrants' attraction is typically for commuting systems. In local centers numerous streams of commuters with small migration attraction coefficients are converge due to the shortage of local workforce and at one time a significant number of jobs.

Some territories along the Bavaria borders remain outside the systems. Migration relations with the cities and districts of the federal state are either absent or weak, and centers attracting migrants from Bavarian territories lie out of Bavaria. For example, in 2013 more than $50 \%$ of employees from Neu-Ulm went to work in city of Ulm (in the Baden-Württemberg federal state), separated from the first by the Danube, and up to $40 \%$ of commuters from Lindau preferred to go to Ravensburg district (also in Baden-Württemberg) with its diversified economy.

Non-return migration systems and commuting systems are comparable both by the migrant number and by the coverage of the territory. Approximation of commuting systems size to the size of non-return migration systems reflects new trends in the development of migration processes. The growth of commuting systems' areas is associated with the expansion of individual radius of commuting (distance people ready to overcome every day, reaching place of work or study). 


\section{Use of human activity density index}

Analysis of population mobility from space-time approach position is carried out by calculating indicators of summarized human activity and its density. According to it the summarized human activity indices cities of Munich (almost 12.0 billion man-hours), Nuremberg (over 4.2 billion manhours) and Augsburg (almost 2.3 billion man-hours) as well as many districts near independent cities are stand out. For most districts and cities of Bavaria average human activity density values are characteristic (Fig. 8). Against this backdrop, the largest cities (together with closest areas) are stand out by human activity density: Munich surpassing an order of magnitude other administrative divisions in terms of the number of man-hours spent here by residents and population temporarily present on the territory (38.2 million man-hours per $\mathrm{km}^{2}$ ), Nuremberg (22.7 million people-hours per $\mathrm{km}^{2}$ ), Augsburg and Regensburg (both by 15.5 million people-hours per $\mathrm{km}^{2}$ ). Very low human activity density was record in 4 regions (in the northeast, near Baden-Württemberg border and around the city of Straubing).

Contribution of migration flows to the total sum of man-hours reflects their role in the whole population mobility process. By using shares of man-hours for different mobility types in the human activity index six groups of districts and cities can be distinguished (shares over $5 \%$ from the total sum were examined). Detection of dominant mobility type in each administrative unit is relative because the sum of man-hours doesn't directly include time of educational migration due to lack of statistical data. For all regions in the sum of man-hours the largest share falls on time lived here by permanent population. There are areas (Fig. 9) of the combination of non-return migration

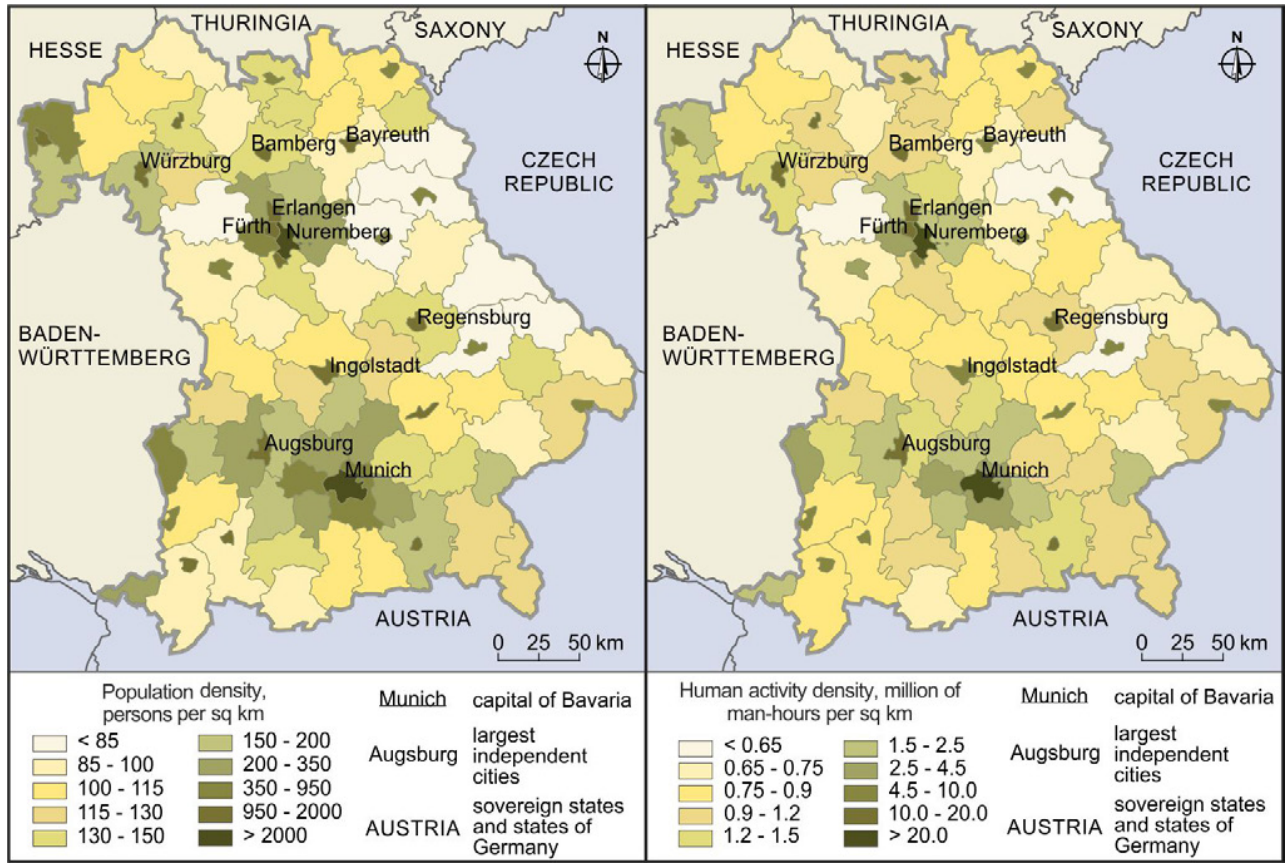

Figure 8. Population density (person per $\mathrm{km}^{2}$ of inhabited area) and human activity density (man-hours per $\mathrm{km}^{2}$ of total area, include territories without permanent population) in districts and independent cities of Bavaria in 2012 (calculated from data of Bavarian state office for statistics) 
(resettlements) with the commuters' inflow (group 1), with the departure of residents to work in other units (group 2), as well as with tourist mobility (group 3); where resettlements are more important than return migration (group 4); with the tourism dominance (group 5); without some migration type dominance (group 6).

Commuting influences the most urbanized areas where migration from land areas and dormitory towns to agglomerations' centers and back predominate. As a striking example of the above-mentioned area of the group 1 the city of Schweinfurt can be named: economy of this important industrial center and at the same time a medium-sized city largely depends on the commuters' inflow (their contribution to the sum of man-hours is almost 17\%). The contrary example is the city of Fürth as a large suburb of Nuremberg. It stands out in the group 2 supplying workers for one of the largest Bavarian cities. Tourism plays an important role by significantly increasing the human activity for the south territories and Bavarian border areas in the east and in the north-west with a modest number of locals and sometimes with their migratory outflow. Here Miesbach can be noted: more than 6 million tourists visit these picturesque places every day for one-day excursions, over 0.5 million rest on the lakes and in the mountains during a year, near the southern border second home tourism spreads. In peripheral and semi-peripheral areas with intensive residents' outflow non-return migration stands out against a background of other population mobility types. The shortage of data on the contribution of educational migration to the sum of man-hours has not allowed to identify regions with its dominance, but one can suppose the significance of ed-

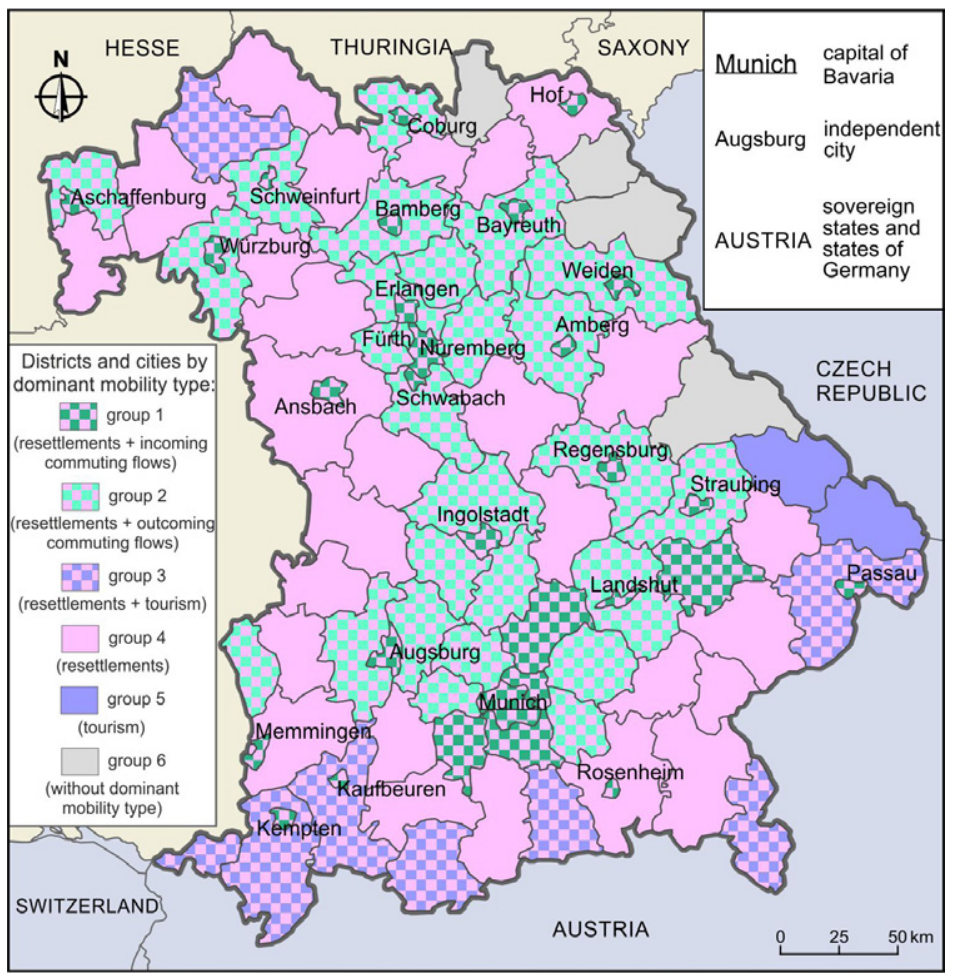

Figure 9. Groups of districts and independent cities of Bavaria by dominant type of population mobility in 2012

Source: author's own elaboration 
ucational migration for university towns (like Augsburg and Passau), as well as for medium-sized cities, where educational services sector is one of the main parts of urban economy (although they are inferior to Munich or Nuremberg in number of students).

Comparing map of human activity density with map of population density (as two representations of load exerted on the territory by various categories of the population) one can be sure that the number of residents in the areas on the periphery of urban agglomerations is "overestimated". In some districts as well as in the most of independent cities balance is shifted in the opposite direction. Here the reverse process plays an important role. This means that here human activity density is formed not only due to residents but also with the active participation of different visitors.

The use of human activity density indicator "animates" some of the outskirts of Bavaria (including the alpine foothills of southern Swabia which looked deserted when using population density indicator), the territory of Bavaria outside its main centers looks more evenly alive than it is according to population density index. Areas with a low human activity density are few, and the backdrop for the largest centers with very high human activity density is area more homogeneous by this indicator values. General picture of the settlement at the territory (reflected in indicators of human activity density) gives an idea of the real degree of economic development of Bavarian regions, corresponds to high population mobility and reflects trends of migration processes and territorial organization of society.

\section{Conclusion}

Population mobility within Bavaria borders is larger than cross-border mobility with other federal states of Germany. Return migration takes more and more important positions in the spatial mobility of population, resettlements are inferior to return migration in terms of number of migrants and frequency of movements. The main zone of non-return migration intensity is situated in the central part of Bavaria and include its key economic centers which form the areas of migrant attraction with different migration dynamics. The number of commuters is growing in Bavaria at all territorial levels and is under the influence of the labor market. The main "employers" are administrative region of Upper Bavaria led by Munich and administrative region of Middle Franconia with Nuremberg. There are three main types of municipalities of Bavaria due to commuting process: "employers", "bedroom communities" and "mixed". Migration systems represent primary areas of attraction of non-return and return migrants to cities and reflect different social and economic bonds between districts and cities. The analysis of the main systems confirmed the dominance of Munich and Nuremberg as the main migration foci and, thus, the bipolarity of the spatial structure of Bavaria. The convergence of the sizes of the non-return migration systems and commuting systems points to the strengthening role of return spatial mobility. Modeling of the human activity density through a special algorithm showed that considering of permanent population mobility and mobility of population temporarily present on the territory, area of Bavaria looks more evenly alive than it is according to the index of population density. The calculation of the human activity density is important for relatively sparsely populated areas with high activity of population temporarily present on the territory, for example commuters and tourists. It is return migrants that increase uniformity of human activity distribution in Bavaria. This conclusion is consistent with the level of economic development of the federal state and with the level of different migration processes activity. It is evidencing also in favor of a spatio-temporal approach to the analysis of spatial mobility of the population. 


\section{Acknowledgements}

The study was financially supported by the Russian Scientific Foundation (project N 14-18-00083 "The Geography of Recurrent Mobility of the Population in the Rural-Urban Continuum" for the Institute of Geography, Russian Academy of Sciences).

\section{References}

Abraham M., Schçnholzer T., 2009. Pendeln oder Umziehen? Entscheidungen über unterschiedliche Mobilitätsformen in Paarhaushalten. [in:] P. Kriwy (ed.), Klein aber fein! Quantitative empirische Sozialforschung mit kleinen Fallzahlen. Wiesbaden: VS, pp. 247-268.

Acker K., 2011. Vorausberechnung der Bevölkerung mit Migrationshintergrund in Bayern bis 2022. Bayern in Zahlen, vol. 65, no. 11, pp. 611-625.

Eckey H.F., Kosfeld R., Türck M., 2006. Abgrenzungen deutscher Arbeitsmarktregionen. Raumordnung und Raumforschung, vol. 64, pp. 299-309.

Ellegård K., 1999. A time-geographical approach to the study of everyday life of individuals - a challenge of complexity. GeoJournal, vol. 48. pp. 167-175.

Fawcett J.T., 1989. Networks, Linkages, and Migration Systems. International Migration Review, vol. 23, pp. $671-680$.

Ficklscherer S., 2011. Einbürgerungen 2010 in Bayern. Bayern in Zahlen, vol. 65, no. 12, pp. 689-692.

Hägerstrand T., 1970. What about people in regional science? Papers of the Regional Science Association, vol. 24, pp. 7-21.

Hägerstrand T., 1985. Time-geography: focus on the corporeality of man, society and environment. [in:] S. Aida (ed.). The Science and Praxis of Complexity. Tokyo: United Nations University Press, pp. 193-216.

Ivakhnyuk I. V., 2007. Evraziiskaya migratsionnaya sistema. Vestnik Moskovskogo universiteta. Seriya 6. Ekonomika, vol. 3, pp. 37-56.

Kalter F., 1994. Pendeln statt Migration? Die Wahl und Stabilität von Wohnort-Arbeitsort-Kombinationen. Zeitschrift für Soziologie, vol. 23, pp. 460-476.

Kramer F., 2008. Aspekte der Modernisierung Bayerns. Geographische Rundschau, vol. 10, pp. 10-15.

Kritz M. M., Lim L. L., Zlotnik H. (eds), 1992. International Migration System: A Global Approach. Oxford: Clarendon Press.

Kropp P., Schwengler B., 2008. Abgrenzung von Wirtschaftsräumen auf der Grundlage von Pendlerverflechtungen. Ein Methodenvergleich. IAB-Discussion Pap., vol. 41, http://doku.iab.de/discussionpapers/2008/dp4108.pdf [14 July 2018].

Lenntorp B., 1976. Paths in Space-Time Environments: A Time-Geographic Study of Movement Possibilities of Individuals. Lund Studies in Geography, Series B, Human Geography, 44, Lund: Royal University of Lund, Department of Geography.

Lenntorp B., 2003. The drama of real-life in a time-geographic disguise. Gèmes rencontres Théo Quant: nouvelles approches en géographie théorique et quantitative, $h t t p: / / c i t e s e e r x . i s t . p s u . e d u / v i e w d o c /$ download?doi=10.1.1.454.8684\&rep=rep1\&type=pdf [14 July 2018].

Mabogunje A. L., 1970. Systems approach to a theory of rural-urban migration. Geographical Analysis, vol. 2, pp. 1-18.

Pfaff S., 2012. Pendeln oder umziehen? Mobilitätsentscheidungen in Deutschland zwischen 2000 und 2009. Zeitschrift für Soziologie, vol. 41, no. 6, pp. 458-477.

Popp M., 2006. München. Boomende Stadtregion mit "Schönheitsfehlern". Geographische Rundschau, vol. 58 , no. 6 , pp. $14-21$.

Roncandor T. A., 2004. Die Wanderungen in Bayern in langfristiger Betrachtung. Bayern in Zahlen. Zeitschrift des Bayerischen Landesamts für Statistik und Datenverarbeitung, vol. 58, no. 10, pp. 373-378. 
Seibert H., 2013. Regionale Mobilität bei Auszubildenden mit deutscher und nicht-deutscher Staatsangehörigkeit. Soziale Ungleichheit und demografischer Wandel. Jahrestagung 2013 der Deutschen Gesellschaft für Demographie e.V. Berlin.

Zelinsky W., 1971. The Hypothesis of The Mobility Transition. Geographical Review, vol. 61, pp. 219-249.

(c) (i) 